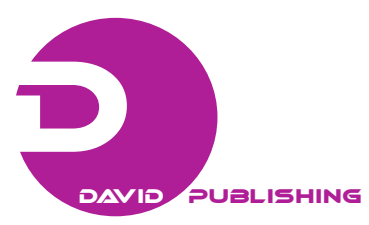

\title{
Multi-Year Observation of Lung Cancer Metastases to the Spleen
}

\author{
Marek Chorąży ${ }^{1}$, Marta Majcher ${ }^{1}$, Katarzyna Fedyszyn Urbanowicz ${ }^{1}$ and Robert Kwiatkowski ${ }^{2}$ \\ 1. Department of Clinical Oncology and Internal Medicine, St. Leszczyński Hospital, Katowice 40-074, Poland \\ 2. Radiotherapy Department, St .Leszczyński Hospital, Katowice 40-074, Poland
}

Received: March 06, 2013 / Accepted: April 10, 2013 / Published: July 25, 2013.

\begin{abstract}
The purpose of our study was to show if there is any correlation between the location of the primary cancer site in the lungs, and the appearance of metastases in the spleen. 1,998 patients with confirmed lung cancer were analyzed. In 22 out of 22 cases, splenic lesions were detected by both, computer tomography (CT) and ultrasound (US) in all 22 of them. All patients with splenic lesions detected by the US underwent US-guided biopsy. Among these patients, metastases to the spleen were histopathologically confirmed in all 22 cases. 18 metastases in the spleen originated from left lung tumors, 3 from right lung tumor. In the 1 case remaining, a pattern of benign lesion was confirmed. The authors came to the conclusion that lung cancer metastases detected in the spleen originate mainly from the left lung cancer which can be caused by higher blood flow to the left lung as compared to the right lung.
\end{abstract}

Key words: Computer tomography, fine needle biopsy, lung cancer, metastasis, spleen, ultrasound.

\section{Introduction}

Metastases to organs such as the liver, bones or central nervous system appear to be a frequent complication of malignant lung cancer. Metastases of lung cancer to the spleen are a great rarity and they are described sporadically $[1,2]$.

Splenic resistance for metastatic seeding is probably due to its high density of immune-system cells and high concentration of angiogenesis inhibition factor $[3,4]$.

Splenic lesions are most often incidentally detected on imaging tests requested for other conditions. Primary spleen tumors are extremely rare [5]. Primary cysts acquiring enormous proportions and haemangiomas are classified as benign tumors $[6,7]$ Metastatic lesions and inflammatory pseudotumors may also be seen, but only very rarely and usually as casuistry $[8,9]$. Splenic lesions may be observed in the course of malignant lymphoma [10, 11] Lesions

Corresponding author: Marek Chorąży, Ph.D., associate professor, research fields: oncology, ultrasound and internal medicine. E-mail: marekchorazy@wp.pl. characteristic of sclerosing angiomatoid nodular transformation (SANT) have also been described [12].

In most cases, the typical characteristics of splenic tumors are established on the basis of histopathological findings, which are obtained by the surgical removal of the tumor or by post-mortem examination [7, 13-15].

In the medical literature, fine needle biopsy performed under ultrasound (US) guidance is considered to be the method of choice in obtaining histopathological diagnosis in splenic tumor [16-20].

Having vast experience in performing biopsies [20-23], we decided to take biopsies of metastatic deposits located in the spleen. These deposits were identified on routine computer tomography (CT) scans in patients diagnosed with lung cancer.

There are cases of regional dissemination of malignant cells described in the medical literature [13] as well as some cancers' affinity for metastasizing to certain organs [24]. 
Therefore, the purpose of our study was to show, based on the observation of many cases, if there is any correlation between the location of the primary cancer site in the lungs and the appearance of metastases in the spleen.

In our study, the differentiation between malignant and benign tumors (on the basis of imaging tests and fine needle biopsy) was also considered, as such differentiation is of fundamental importance in patients' treatment.

\section{Patients and Methods}

Our study was conducted from January 2003 to November 2012. In the group of 2,340 patients, 1,998 were diagnosed with lung cancer (initially classified as located only in one lung, T1, T2, T3, T4). In this group in $19(0.95 \%)$ cases splenic lesions (metastatic and benign) were revealed.

While the 342 cases with disseminated lung cancer (M1a, M1b) metastasizing to the liver, bones, central nervous system and mediastinal lymph nodes were rejected as it was impossible to determine in which lung the primary cancer site was based. In this group in $3(0.87 \%)$ cases, the metastatic lesion in the spleen was revealed (Table 1).

All analyzed patients were diagnosed with lung cancer for the first time. Histopathological diagnoses of the lung tumors were made on the basis of previously conducted investigations during which specimens were taken intraoperatively and during flexible bronchoscopy. All patients received treatment in the Oncology Department and Ambulatory in St. Leszczyński Hospital, Katowice. Our project has received approval from the Commission of Ethics and all patients were given detailed information about
US-guided biopsy and consented to the procedure. Siemens Somatom AR.TX, Siemens Somatom Sensation Open, US Hitach EUB 515 and Logiq C5 were used to visualize the spleen. Specimens were taken with $1.2 \mathrm{~mm}$ diameter biopsy needles. All pictures submitted in our manuscript were taken during the study.

In the group of 1,998 patients with single lung cancer, splenic lesions were detected using both $\mathrm{CT}$ (Fig. 1), and US in 22 of them (1.10\%) (Figs. 2 and 3). All splenic lesions included in our analysis measured at least $2 \mathrm{~cm}$ in diameter. The group of 22 patients with confirmed splenic lesions underwent the diagnostic biopsy. Specimens were taken with $1.2 \mathrm{~mm}$ diameter biopsy needles (Figs. 4-6). In 1 case the tumor spread into the spleen as well as into the left adrenal gland and this case was published already separately [20]. The biopsy had to be done twice in 2 cases in order to obtain clear histopathological results. There were several pre-biopsy requirements which included: informed consent, prothrombin activity greater than $70 \%$, a platelet count higher than $80,000 / \mu \mathrm{l}$ and $12 \mathrm{~h}$ of fasting before the biopsy. But our experience with the ultrasound-guided fine-needle biopsy of a spleen showed that, if performed under ultrasound guidance with appropriate blood clotting parameters, splenic biopsy in the evaluation of new or recurrent neoplasm is a minimally invasive procedure with low complication rates and a high diagnostic yield. The safety of spleen biopsy was confirmed by others authors as well [17-20].

Binomial test was applied to statistical studies based on the incidence of splenic metastasis from cancer of the left or right lung.

Unfortunately, it was only possible to perform PET

Table 1 The number of splenic metastasis depending on the location of the tumor in the lung $(n=2343)$.

\begin{tabular}{llc}
\hline The location of the primary tumor & $\begin{array}{l}\text { Tumor located only in one lung, T1, } \\
\text { T2, T3, T4 }\end{array}$ & Number of metastatic lesions in the spleen \\
\hline Left lung & 1,998 & $18(0.9 \%)$ \\
Right lung & 345 & $3(0.15 \%)$ \\
$\begin{array}{l}\text { Disseminated lung cancer } \\
\text { M1a, M1b }\end{array}$ & $3(0.87 \%)$ \\
\hline
\end{tabular}




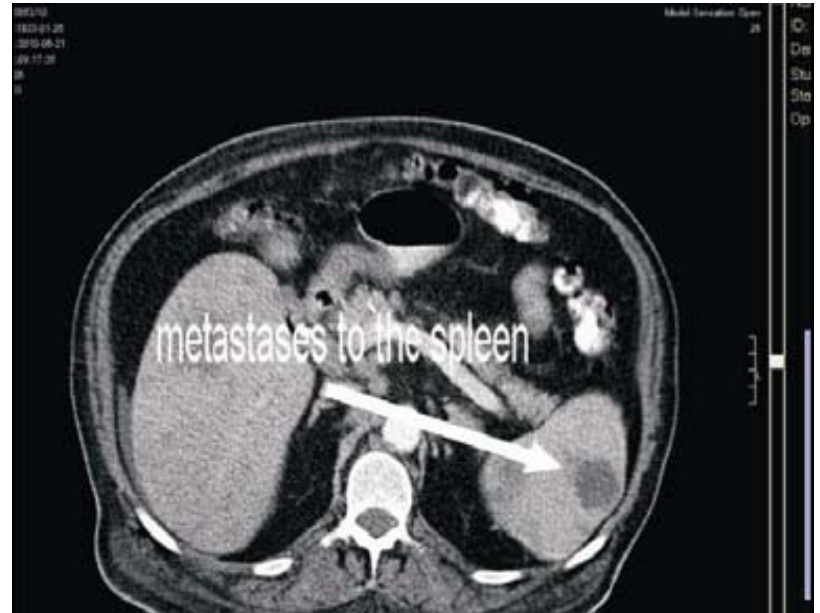

Fig. 1 Computer tomography image, metastases to the spleen from left lung carcinoma.

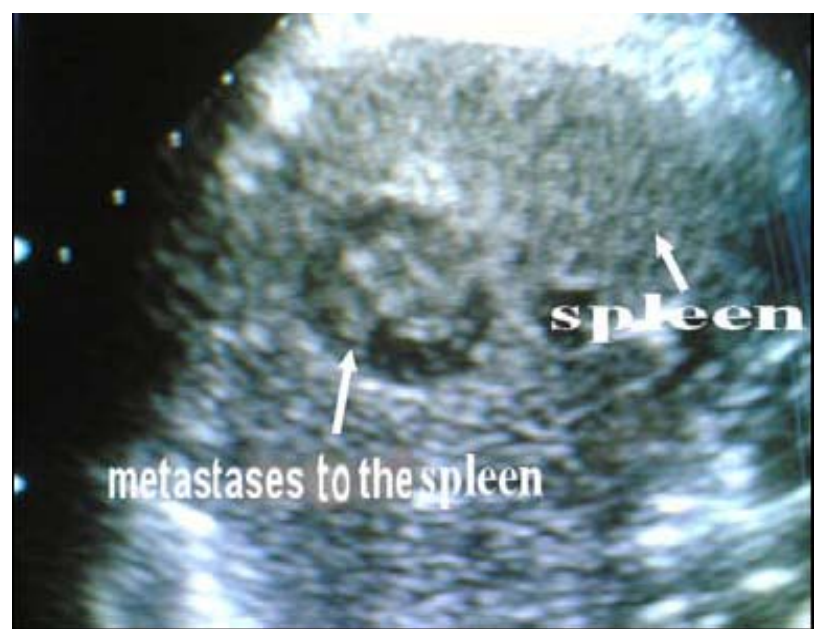

Fig. 2 Ultrasound image, splenic metastases from left lung cancer.

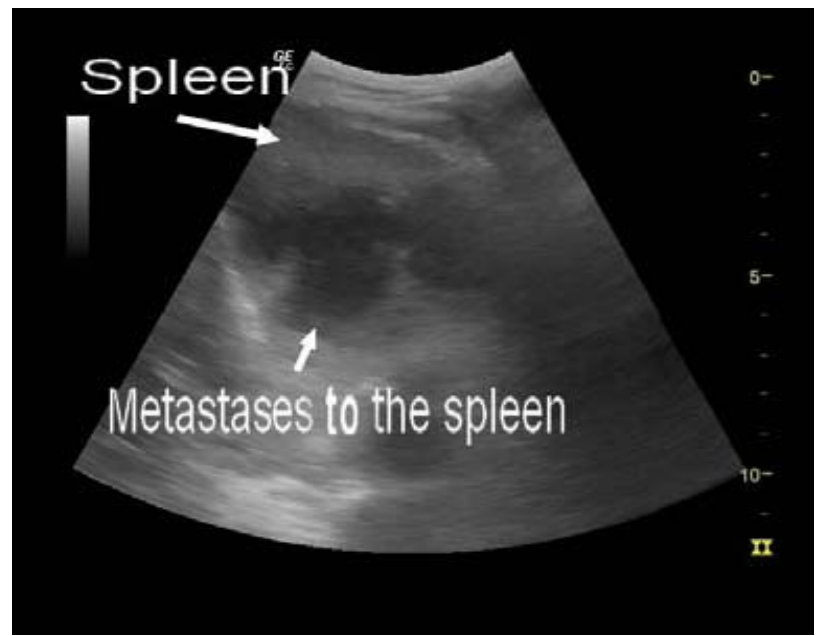

Fig. 3 Ultrasound image, splenic metastases from left lung cancer.

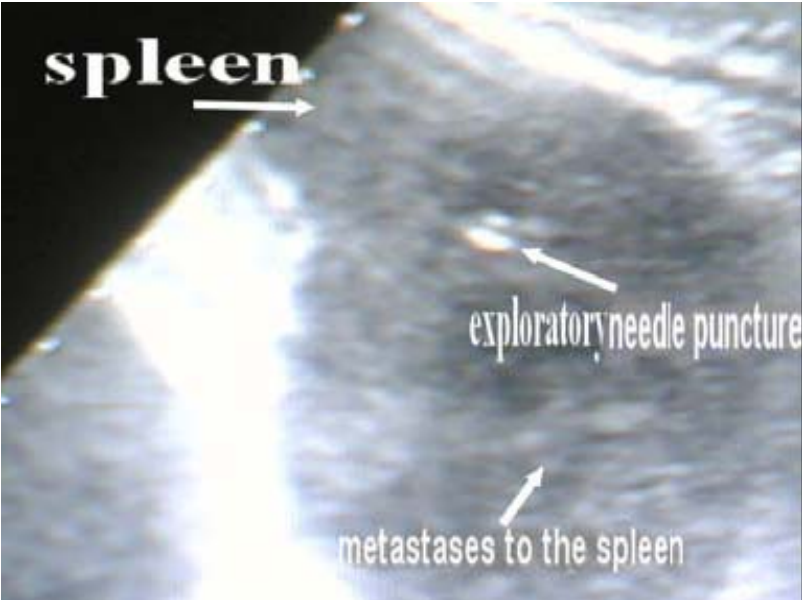

Fig. 4 Ultrasound image, biopsy needle in a spleen tumor.

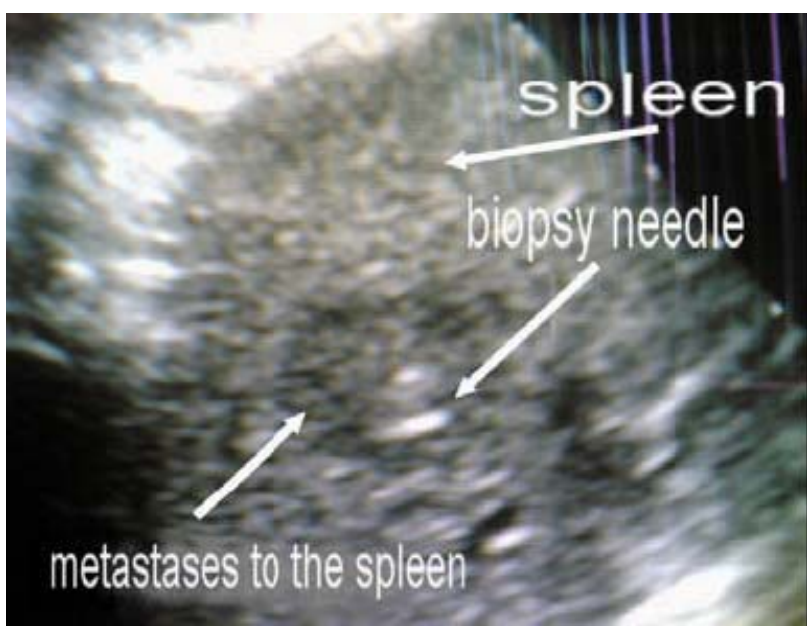

Fig. 5 Ultrasound image, puncture needle in metastases to the spleen.

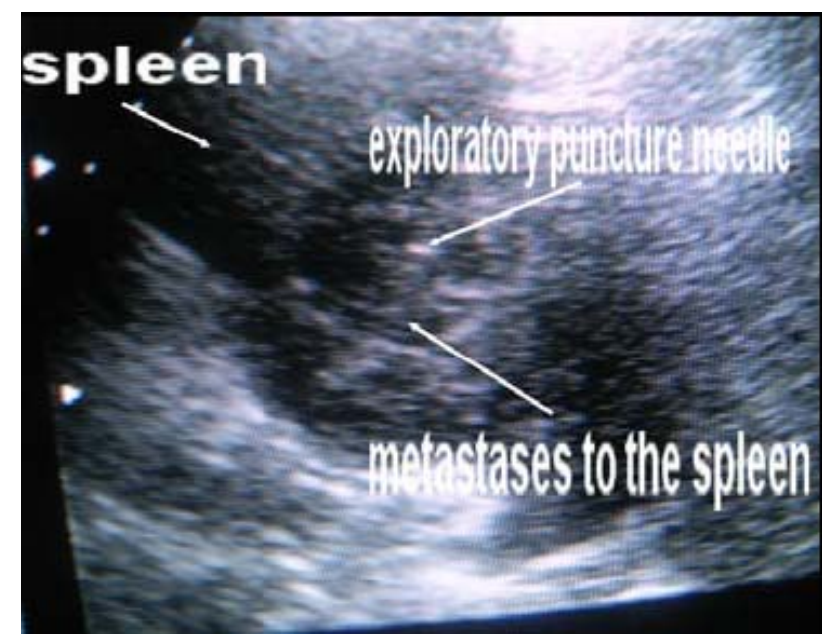

Fig. 6 Ultrasound image, biopsy needle in a spleen tumor. 
scans on less than half of the patients and the results we obtained were ambiguous, even in biopsied patients with histopathological confirmation of metastasis in the spleen. Under these circumstances we decided to omit the analysis of the PET scan reports in our study.

\section{Results}

In 22 out of 1,998 patients with lung cancer confirmed by histopathology, a pathological spleen structure was found on $\mathrm{CT}$ scans during their treatment. In all 22 cases, the lesions (all with a diameter greater than $2 \mathrm{~cm}$ ) were shown by ultrasonography and US-guided biopsies were performed. In 21 of them, the histopathological report confirmed a malignant pattern of lung metastases: in 15 patients non-small cell lung cancer (squamous cell carcinoma or adenocarcinoma) and in 6 patients small cell carcinoma were confirmed. In 1 of 6 cases, the same type of cancer as in the left lung was observed in the adrenal gland and in the spleen, metastases of small cell cancer [20].

In 18 cases, the primary cancer site was located in the left lung. Only in 3 cases primary lung tumor was situated in the right lung. In 1 case of cancer tumor located in the right lung, a pattern of benign lesion in the spleen was confirmed (angioma) (Table 2).

\section{Disscusion}

In the existing literature, we found only few cases of a lung cancer metastases to the spleen $[1,14,15]$. There are also some descriptions of metastases isolated in spleen from others organs [13]. Simultaneous metastases of lung cancer to the adrenal gland and the spleen (apart from our publication) have never been described [20].

Splenic lesions included in our study were greater than $2 \mathrm{~cm}$ in diameter and therefore, could be diagnosed by biopsy. It is also interesting to analyze the location of the lesions in the lungs in comparison to metastases in the spleen. In 18 (72.72\%) analyzed cases of lung tumors metastasizing to the spleen, primary lung cancer lesions were found in the left lung in $3(13.63 \%)$ cases in the right lung. Both non-small cell lung cancer (72.72\%) and small cell lung cancer (27.28\%) spread to the spleen with similar frequency. In the 1 case remaining, a pattern of benign lesion was confirmed (angioma). This represents $4.54 \%$ of all the examined patients.

According to our research, lung cancer metastases to the spleen predominantly come from the left lung $(86.36 \%)$. We wonder if such directional conditionality of the isolated metastases' location in the spleen (depending on the original location of the tumor in the lung) can be related to the higher blood flow to the left

Table 2 Characteristics of splenic lesions found in 1998 patients with lung cancer $n=22(1.10 \%)$ cases.

\begin{tabular}{|c|c|c|c|}
\hline \multirow{2}{*}{ Tumor subtypes } & \multirow{2}{*}{ Number of cases } & \multicolumn{2}{|c|}{ Sex } \\
\hline & & male $n=13$ & female $n=9$ \\
\hline Squamous cell carcinoma & 7 & 4 & 3 \\
\hline or adenocarcinoma $n=15(68.18 \%)$ & 8 & 4 & 4 \\
\hline Small cell carcinoma $n=6(27.27 \%)$ & 6 & 4 & 2 \\
\hline Angioma $n=1(4.54 \%)$ & 1 & 1 & \\
\hline a. Primary cancer site: left lung & $\begin{array}{l}18(81.82 \%) \\
\text { (in spleen and in left adrenal gland } n=1 \text { ) }\end{array}$ & 11 & 7 \\
\hline b. Primary cancer site: right lung & $\begin{array}{l}\text { Tu malignant } 3(13.64 \%) \\
\text { Tu benin } 1(4.54 \%)\end{array}$ & $\begin{array}{l}\text { Squamos cell } \\
\text { Angiona } 1\end{array}$ & Adenoca 1 \\
\hline
\end{tabular}

a to $\mathrm{b}$ Binomial test, statistically significant differences $p<0.01$

The thesis (so-called "the null hypothesis") states that the probability of occurrence of the splenic metastasis is identical (equal to 0.5 ) regardless of which lung (left or right) is affected by cancer.

The alternative hypothesis assumes that the probability of splenic metastasis occurrence is greater than 0.5 if the left lung is affected. 
lung as compared to the right lung, many researchers reach the same conclusion [15], but in our opinion this phenomenon requires further study.

In our study, in one case the presence of left lung carcinoma metastases simultaneously in the left adrenal gland and the spleen were observed [20]. This also confirms the described mechanism of tumor dissemination to the spleen.

In our material, only in 3 cases cancer tumor situated in the right lung metastasized to the spleen (13.64\%) (Table 2).

We identified a tendency of splenic metastases to originate more often in the left lung than in the right lung, which was described in the medical literature previously, but was mainly based on post-mortem examination [14]. Our observations, however, were made during classifying patients for treatment while still alive, which can probably account for the small disparities in the results.

We noticed $100 \%$ of splenic lesions (greater than 2 $\mathrm{cm}$ in diameter) could be visualized by US. All metastatic deposits found in the spleen had left lung origin. In our opinion, this direction depended on the location of the primary cancer site. This observation is important in predicting further diagnosis and treatment, especially in departments which do not have the option of biopsying the spleen, or in cases when performing a biopsy is otherwise impossible.

Observation of the patients with lung cancer metastases to the spleen led us to another conclusion: There was no correlation between patients sex, the histological type of cancer, and the location of the metastases.

In our opinion, the relatively small number of cases (3 of 342) with metastatic dissemination is most likely the result of limited time for tumor growth in the spleen (due to tumors' rapid progression and dissemination to other parts of the body). Although we cannot determine the location of the primary cancer site in the lungs in this group, the incidence rate of the observed splenic metastases ( 3 of 342 cases, $0.87 \%$ ) is similar to the incidence rate of splenic metastases originated only in the left lung (18 of 1,998 cases, $0.9 \%$ ) (Table 1).

Despite the ambiguous explanation of the observed findings, considering the significant practical value of these observations, in our opinion, the obtained results could be incredibly helpful in making decisions regarding patients' treatment.

\section{Conclusions}

(1) Lung cancer may return in $1.05 \%$ of cases as metastasis to the spleen;

(2) Splenic metastases from lung cancer originate significantly more often from the left lung as compared to the right lung cancer;

(3) The observed prevalence of left lung cancer metastases to the spleen can be related to the higher blood flow to the left lung as compared to the right lung;

(4) The incidence rate of the observed splenic etastases in patients with disseminated lung cancer is similar to the incidence rate of splenic metastases originated only in the left lung;

(5) These findings lead us to another conclusion, that occurrence of the splenic lesions detected incidentally on imaging tests located contralaterally to the primary cancer site in the lungs may suggest its non-metastatic character;

(6) In departments which lack invasive diagnostic methods such as fine needle biopsy, this observation could be helpful when estimating the character of pathological lesions in the spleen. It can also be helpful when trying to qualify patients for surgical treatment.

\section{References}

[1] V. Hut, P. Cools, R. Rutsaert, Solitary splenic metastasis of an adenocarcinoma of the lung, 2 years postoperatively, Acta. Chir. Belg. 108(4) (2008) 462-463.

[2] K.Y. Lam, V. Tang, Metastatic tumor to the spleen, A 25, year cytopathologic study, Arch. Pathol. Lab. Med. 124 (2000) 526-530. 
[3] S. Massarweh, H. Dhingra, Unusual sites of malignancy case 3: Solitary splenic metastasis in lung cancer with spontaneous rupture, J. Clin. Oncol. 19 (5) (2001) 1574-1575.

[4] A. Sanchez-Romero, I. Oliver, D. Costa, A. Orduña, Giant splenic metastasis due to lung adenocarcinoma, Clin. Transl. Oncol. 8 (4) (2006) 294-295.

[5] R. Kochar, C. Vijayasekar, U. Pandey, R. Bhogal, L. Brown, G. Matthew, Primary carcinosarcoma of spleen: Case report of a rare tumor and review of the literature, Int. J. Surg. Pathol. 17 (1) (2009) 72-77.

[6] H. Lee, R. Maeda, Hamartoma of the spleen, Arch. Pathol. Lab. Med. 133 (1) (2009) 147-151.

[7] T. Orawczyk, P. Ćwik, D. Ziaja, M. Kazibudzki, Familia lymphangioma, a rare form of splenic, Cysts. Chir. Pol. 4 (4) (2002) 187-191.

[8] S. Bhatt, R. Simon, V.S. Dogra, Inflammatory pseudotumors of the spleen, Am. J. Roentgenol. 191 (15) (2008) 1477-1479.

[9] M. Tee, P. Vos, P. Zetler, S.M. Wiseman, Incidental littoral cell angioma of the spleen, World J. Surg. Onc. 6 (2008) 87-92.

[10] R. Gupta, S. Naseem, S. Sukumaran, R. Kashyap, S. Kaur, L. Paul, Splenic lymphoma with villous lymphocytes, Indian J. Pathol Microbiol. (2008) 51 (1) 113-115.

[11] F. Takata, H. Kaida, M. Ishibashi, S. Kurata, J. Uozumi, M. Uchida, et al., Primary splenic lymphoma detected by F-18 FDG PET, Clin. Nucl. Med. 33 (3) (2008) 204-207.

[12] A.F. Koreishi, A.J. Saenz, S.E. Fleming, J. Teruya-Feldstein, Sclerosing angiomatoid nodular transformation (SANT) of the spleen: A report of 3 cases, Int. J. Surg. Pathol. 18 (3) (2010) 136S-141.

[13] S.L. Showalter, E. Hager, C.J. Yeo, Metastatic disease to the pancreas and spleen, Semin Oncol. 35 (2) (2008) 160-171.

[14] Kinoshita, M. Nakano, M. Fukuda, T. Kasai, N. Suyama, $\mathrm{K}$. Inoue, et al., Splenic metastasis from lung cancer, Neth. J. Med. 47 (5) (1995) 219-223.

[15] A.R. Dias, R.A. Pinto, J.N. Ravanini, R.M. Lupinacci, I.
Cecconello, U. Ribeiro, Isolated splenic metastasis from lung squamous cell carcinoma, 2012 World J. Surg. Oncol. 10 (1) (2012) 24.

[16] A. Tam, S. Krishnamurthy, E.P. Pillsbury, J.E. Ensor, S. Gupta, R. Murthy, et al., Percutaneus image, guided splenic biopsy in the oncology patient: an audit of 156 consecutive cases, J. Vasc. Interv. Radiol. 19 (1) (2008) 80-87.

[17] L. Cavanna, A. Lazzaro, D. Vallisa, G. Civardi, Role of image, guided fine, needle aspiration biopsy in the management of patients with splenic metastasis, World J. Surg. Oncol. 5 (13) (2007) 1-6.

[18] G. Civardi, D. Vallisa, R. Bertè, A Giorgio, Ultrasound-guided fine needle biopsy of the spleen: High clinical efficacy and low risk in a multicenter Italian study, Am. J. Hematol. 67 (2) (2001) 93-99.

[19] P. Liang, Y. Gao, Y. Wang, X. Yu, D. Yu, B. Dong, US-guided percutaneous needle biopsy of the spleen using 18-gauge versus 21-gauge needles, J. Clin. Ultrasound 35 (9) (2007) 477-482.

[20] M. Chorąży, M. Majcher, K. Fedyszyn-Urbanowicz, G. Bierzyńska-Macyszyn, R. Kwiatkowski, Atypical dissemination of lung cancer to the adrenal gland and to the spleen, Współcz. Onkol. 5 (2012) 444-446.

[21] M. Chorazy, A. Nasiek-Palka, Z. Wiak, Analysis of histopathological examination results concerning biopsy material taken during pancreas, live rand kidney drainage, Współcz. Okol. 2 (2007) 67-71.

[22] M. Chorąży, D. Jabłońska, E. Skrzypek, A. Nasiek-Palka, Several years' observation of the suppurating pancreatic cyst, which eventually turned out to be a cancer, case study, Współcz. Okol. 2 (2009) 102-107.

[23] M. Chorąży, Z. Wiąk, J. Głasek, Bioptic diagnosis of adrenal gland tumors in patients with lung neoplasm's, Współ. Onkol. 12 (2008) 111-115.

[24] S. Eccles, L. Paon, J. Sleeman, Lymphatic metastasis in breast cancer: importance and new insights into cellular and molecular mechanisms, Clin. Exp. Metastasis 24 (6) (2007) 19-636. 